\title{
Separation and Purification of Three Main Lignans from the Anti-Inflammatory Extract of Lllicium Difengpi by High-Speed Counter-Current Chromatography
}

\author{
Desheng Ning, Yixia Fu, Zhenghong Pan ${ }^{\star}$
}

Guangxi Key Laboratory of Functional Phytochemicals Research and Utilization, Guangxi Institute of Botany, Chinese Academy of Sciences, Guilin 541006, China;

*Corresponding author. E-mail: pan7260@126.com

Keywords: Illicium difengpi; Lignans; HSCCC; Magnolol

Abstract. Based on the principle of partition coefficient values $(\kappa)$ for target compounds and the separation factor $(\alpha)$ between target compounds, the optimal two-phase solvent system composed of n-hexane-ethyl acetate-methanol-water $(1: 0.3: 1: 0.2, \mathrm{v} / \mathrm{v})$ was applied for the first time to isolate and purify three main lignans from the anti-inflammatory active extract of bark of Illicium difengpi. Using upper phase as the mobile phase in the head to tail elution model, magnolol (297.6 mg), difengpin $(15.7 \mathrm{mg}$ ), and isodunnianol $(17.5 \mathrm{mg}$ ), with the purities of more than $95 \%$, were obtained from $800 \mathrm{mg}$ of crude extract in a single operation. Additionally, their structures were identified by MS, ${ }^{1} \mathrm{H}-\mathrm{NMR}$ and ${ }^{13} \mathrm{C}-\mathrm{NMR}$.

\section{Introduction}

Illicium difengpi is a toxic shrub that grows in Karst region of Guangxi Province, China. Its stem bark is listed in the Chinese Pharmacopeia as a traditional Chinese medicine to dispel wind, eliminate dampness, reduce swelling and relieve pain. The plant also is used to treat rheumatoid arthritis in Zhuang folk medicine [1]. Lignans, which was recognized as main constituents in Illicium difengpi, usually have significant anti-inflammatory activity [2]. Our previous study proved that the dichloromethane extract of Illicium difengpi exhibited inhibitory activities of mice ear engorgement induced by dimethyl benzene. In this study, three lignans were obtained from this extract by high-speech counter-current chromatography, which structures (Fig.1) were identified by spectroscopic analysis (MS, ${ }^{1} \mathrm{H}-\mathrm{NMR}$ and $\left.{ }^{13} \mathrm{C}-\mathrm{NMR}\right)$.

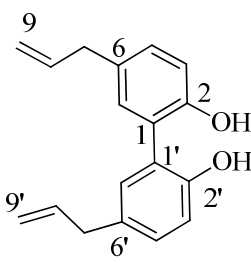

peak 1 (magnolol)

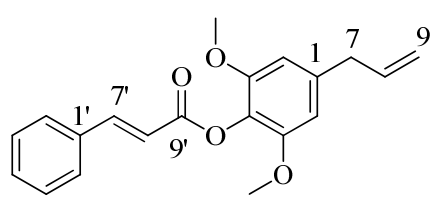

peak 2 (difengpin)

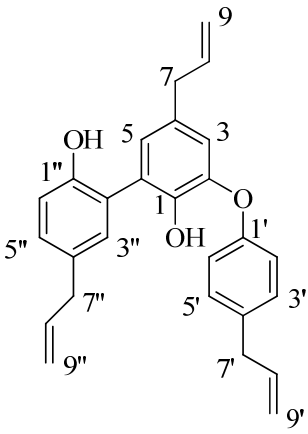

peak 3 (isodunnianol)

Fig. 1 Chemical structures of three main lignans from Illicium difengpi

\section{Experimental}

Reagents and Plant Materials. All solvent used for HSCCC are of analytical grade (XiLong Chemical Co., Ltd. China). Acetonitrile used for HPLC analysis is of chromatographic grade (Fisher Scientific, China). 100-200 mesh silica gel was used to enrich active components (Qingdao Haiyang Chemical Co., Ltd. China).

The bark of Illicium difengpi was collected in Du'an County, Guangxi Zhuang Autonomous Region, China, and identified by Professor Hui Tang, Guangxi Institute of Botany.

Apparatus. HSCCC (TBE-300C, Tauto Biotech, Shanghai, China) equipped with a three multilayer coil separation column connected in coil (i.d. of the tube, $1.9 \mathrm{~mm}$, total volume, $300 \mathrm{~mL}$ ) and a 20 
$\mathrm{mL}$ sample loop. The separation system was also employed a TBP 5002 pump (Tauto Biotech, Shanghai, China), UV2000D detector (Shanghai Sanotac Scientific Instrument Co., Ltd. China), CHF161RA fraction collector (Toyo Seisakusho Kaisha, Ltd. Japan) and Easy Chrom-1000 workstation. The separation temperature was adjusted by DC-0506 low constant temperature bath (Tauto Biotech, Shanghai, China).

The analytical HPLC (LC-2030C 3D, SHIMADZU, Japan) was used for the determination of crude sample and peak fractions from HSCCC. LC-MS-IT-TOF system (Shimadzu, Japan) and Bruker AVANCE III HD $500 \mathrm{MHz}$ NMR system (Bruker Inc., Sweden) was applied to identify the chemical structure of target compounds.

Preparation of Crude Sample. The bark of Illicium difengpi $(1.5 \mathrm{~kg})$ were smashed and percolated three times with dichloromethane $(5 \mathrm{~L})$, following by drying under reduced pressure at $60{ }^{\circ} \mathrm{C}$ to yield $24 \mathrm{~g}$ of crude extract. In order to enrich the anti-inflammatory components, the dried extract was loaded on silica gel column (100-200mesh), and eluted with mixture solvents of petroleum ether and ethyl acetate $(30: 1,10: 1, \mathrm{v} / \mathrm{v})$ in gradient model. And then fractions $(10: 1, \mathrm{v} / \mathrm{v})$ were concentrated with rotary vaporization under reduced pressure at $60{ }^{\circ} \mathrm{C}$ to obtained $3.8 \mathrm{~g}$ of HSCCC sample.

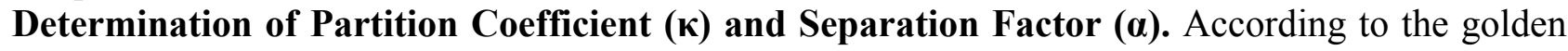
rules for HSCCC [3], the measurements of partition coefficient and separation factor are most importance steps in selecting two-phase solvent systems. In this paper, the determination of $\kappa$-value and $\alpha$-value were performed by HPLC as follows: $1.0 \mathrm{mg}$ of HSCCC sample was weighted into 25 $\mathrm{mL}$ test tube, and dissolved with $5 \mathrm{~mL}$ each of upper and lower phase from pre-equilibrated biphasic solvent system. Then the test tube was shaken vigorously for several minutes to thoroughly equilibrate the sample in both phases. Subsequently, equal volume $(200 \mu \mathrm{l})$ of upper and lower phases were transferred and evaporated to dryness, separately. The residues were diluted with 200 $\mu 1$ of methanol and analyzed by HPLC to obtain the $\kappa$-value of target compound and the $\alpha$-value between both target compounds.

Preparation of Two-Phase Solvent System and Sample Solution. A two-phase solvent system used in this study was consisted of n-hexane-ethyl acetate-methanol-water at volume rate of 1:0.3:1:0.2. The mixture solvent was thoroughly equilibrated in a separator funnel at room temperature, and separated and degassed by sonication 15 minute before use.

The sample solution was prepared by dissolving crude sample in $5 \mathrm{~mL}$ each of both phases of pre-equilibrated biphasic solvent system.

Separation Procedure. The multilayer column was first entirely filled with the upper phase of solvent system as stationary. Then the apparatus was rotated at $800 \mathrm{rpm}$ in forward direction, while the lower phase was pumped into column at a flow rate of $2.0 \mathrm{~mL} / \mathrm{min}$ from heal to tail. The temperature was set at $20^{\circ} \mathrm{C}$. After hydrodynamic equilibrium was reached, $10 \mathrm{~mL}$ of sample solvent included $800 \mathrm{mg}$ of crude sample was injected into column through the injection valve. The effluent was continuously monitored by UV detector at $254 \mathrm{~nm}$ and automatically collected in a $25 \mathrm{~mL}$ test tube for $5 \mathrm{~min}$ by fraction collector. When all target compounds had been eluted, the apparatus was stopped and the stationary phase in column was pushed out to calculate the retention rate of stationary phase. Subsequently, the target peak fractions were manually collected and dried under reduced pressure according to the chromatogram (Fig. 2). 


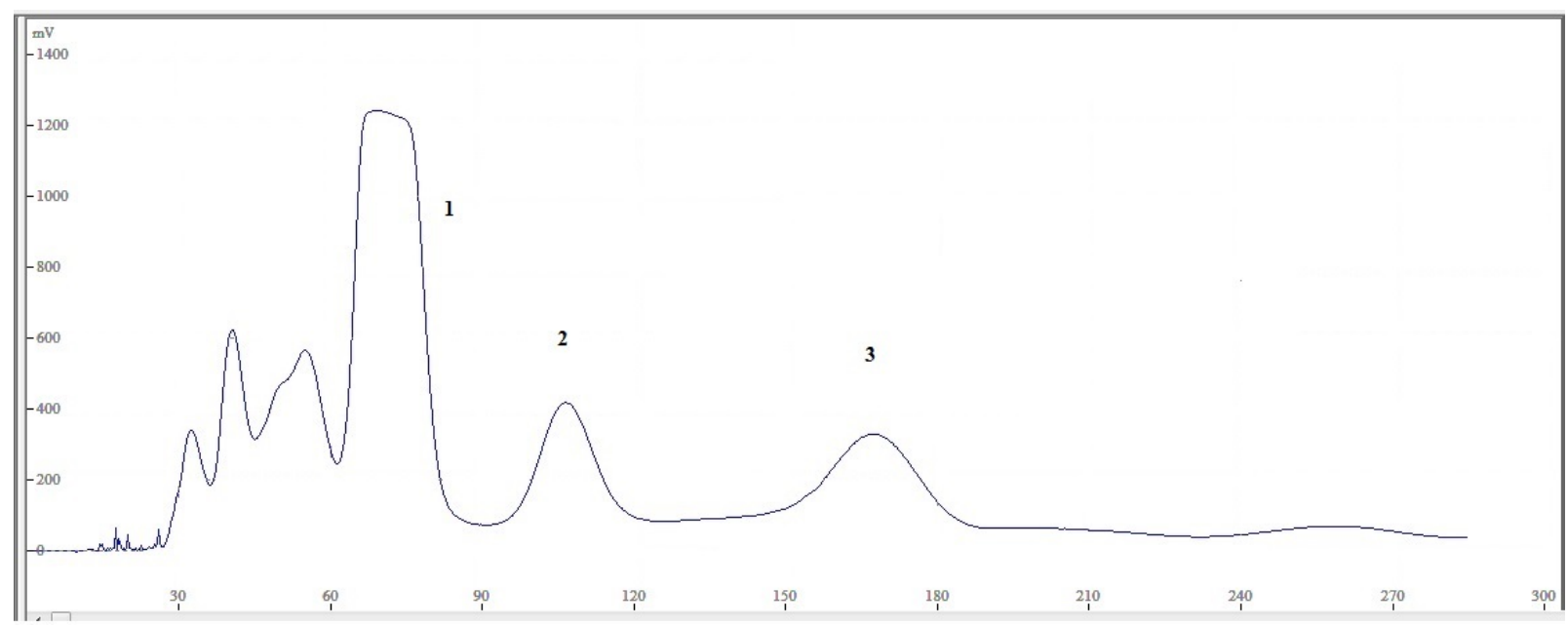

Fig. 2 HSCCC chromatogram of crude extract sample

Analysis and Identification of Target Compounds. The crude sample and each peak fractions were analyzed by HPLC with an Aglient ZORBAX SB-C ${ }_{18}(5 \mu \mathrm{m}, 4.6 \times 250 \mathrm{~mm})$ at $30{ }^{\circ} \mathrm{C}$. The mobile phase composed of acetonitrile and water was used in gradient elution model as follows: acetonitrile: $0-10 \mathrm{~min}: 45-65 \%, 10-25 \mathrm{~min}: 65-85 \%$ and $25-30 \mathrm{~min}, 85 \%$. The flow rate of mobile phase was kept at $1 \mathrm{~mL} / \mathrm{min}$ and the effluent was monitored at $254 \mathrm{~nm}$ (Fig. 3).

The target peak fractions were identified by analyzing their spectroscopic data and comparing with published literature. 

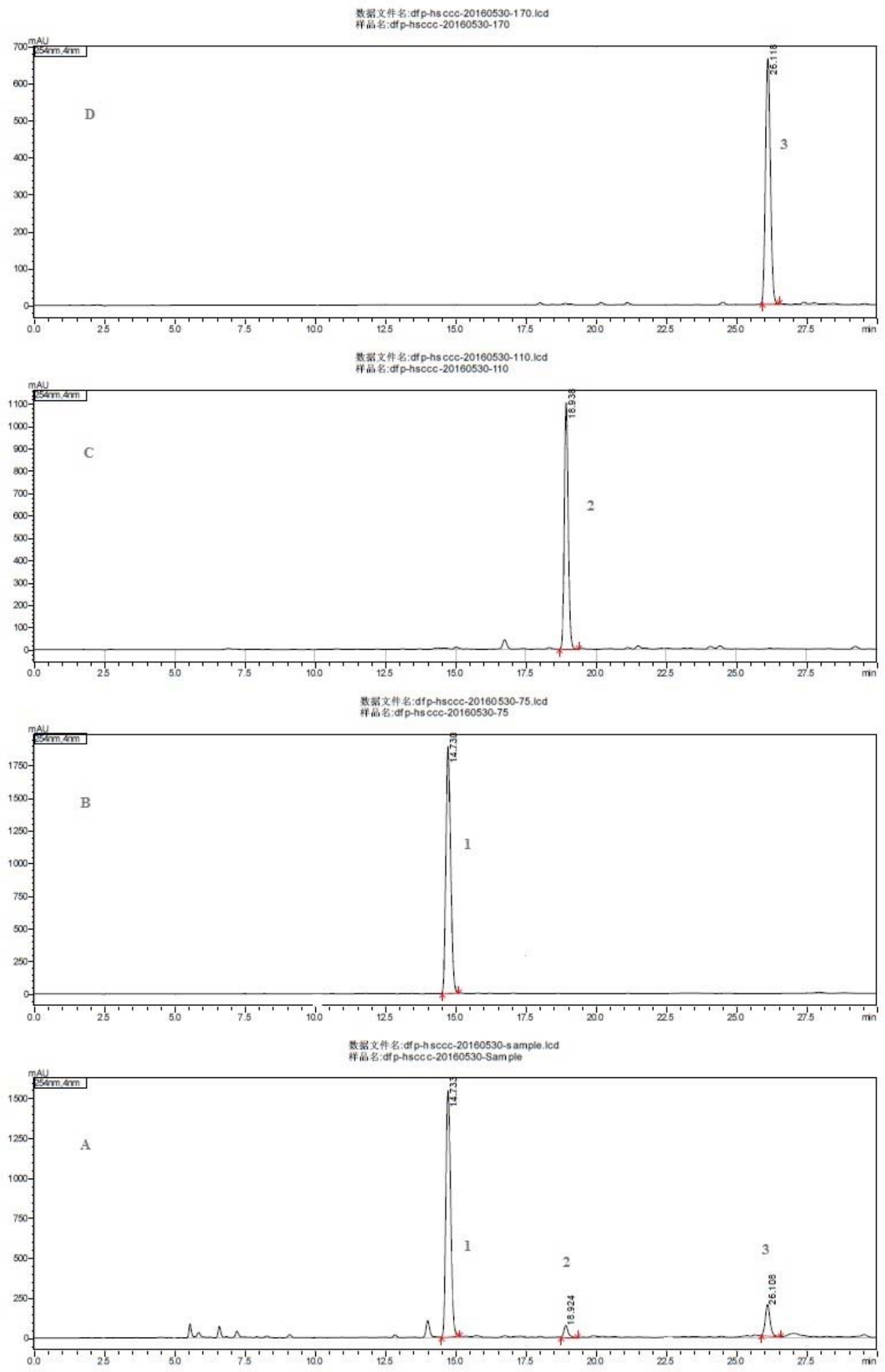

Fig. 3 Chromatograms of crude extract sample and target peak fractions. A: crude extract sample, B: peak 1 (magnolol), C: peak 2 (difengpin), D: peak 3 (isodunnianol)

\section{Results and Discussion}

Selection of Two-Phase Solvent System. The successful HSCCC separation acquired a suitable solvent system. Based on the analysis of the chromatographic behavior of magnolol in HSCCC $[4,5]$, n-hexane-ethyl acetate-methanol-water was first considered as biphasic solvent system to 
search ideal partition coefficient and separation factor of target compounds in different volume rate of solvent system. Usually, the ideal $\kappa$-value was considered in the range of 0.5-2 [6], and $\alpha$-value ought to be greater than $1.5\left(\alpha=\mathrm{k}_{1} / \mathrm{k}_{2}\right.$, where $\left.\mathrm{k}_{1}>\mathrm{k}_{2}\right)$. In our study, the screening results presented in Table 1 show that the biphasic solvent systems (1:0.3:1:0.2 and 1:0.6:1.5:0.2, v/v) provided accepted $\kappa$-values for target compounds, but the $\alpha_{12}$ value in selected solvent systems indicated the biphasic solvent systems (1:0.3:1:0.2, v/v) had a greater resolution for compounds 1 and 2 . Thus this solvent system was applied for the HSCCC separation. Additional, the retention of stationary phase also is an importance influence factor [3], and the retention of $76 \%$ was achieved in present study.

Table 1 The partition coefficient and separation factor of three anti-inflammatory compounds in different solvent systems.

\begin{tabular}{ccccccc}
\hline \multirow{2}{*}{$\begin{array}{c}\text { n-hexane-ethyl } \\
\text { acetate-methanol-water }\end{array}$} & \multicolumn{3}{c}{ א value } & \multicolumn{3}{c}{$\alpha$ value } \\
\cline { 2 - 6 } & Compound & Compound & Compound & $\alpha_{12}$ & $\alpha_{13}$ & $\alpha_{23}$ \\
\hline $1: 0.1: 1: 0.2$ & 0.13 & 0.34 & 0.53 & 2.62 & 4.08 & 1.56 \\
$1: 0.2: 1: 0.2$ & 0.28 & 0.52 & 1.04 & 1.86 & 3.71 & 2.00 \\
$1: 0.3: 1: 0.2$ & 0.38 & 0.58 & 1.12 & 1.53 & 2.95 & 1.93 \\
$1: 0.2: 0.8: 0.2$ & 0.28 & 0.51 & 1.07 & 1.82 & 3.82 & 2.10 \\
$1: 0.2: 1.3: 0.2$ & 0.25 & 0.42 & 0.72 & 1.68 & 2.88 & 1.71 \\
$1: 0.3: 1.2: 0.2$ & 0.16 & 0.26 & 0.41 & 1.63 & 2.56 & 1.58 \\
$1: 0.4: 1.3: 0.2$ & 0.32 & 0.44 & 0.79 & 1.38 & 2.47 & 1.80 \\
$1: 0.5: 1.4: 0.2$ & 0.31 & 0.43 & 0.71 & 1.39 & 2.29 & 1.65 \\
$1: 0.6: 1.5: 0.2$ & 0.54 & 0.72 & 1.45 & 1.33 & 2.69 & 2.01 \\
$1: 0.7: 1.6: 0.2$ & 0.23 & 0.26 & 0.38 & 1.13 & 1.65 & 1.46 \\
\hline
\end{tabular}

\section{Structure Identification of the HSCCC Peaks}

Peak 1: white powder. ESI-MS $(\mathrm{m} / \mathrm{z}): 365[\mathrm{M}-\mathrm{H}]]^{-} .{ }^{1} \mathrm{H}$ NMR $\left(500 \mathrm{~Hz}, \mathrm{CDCl}_{3}\right) \delta: 7.08(2 \mathrm{H}, \mathrm{s}, \mathrm{H}-4$, 4'), 7.06 (2H, s, H-6, 6'), 6.88 (2H, d, $J=7.5 \mathrm{~Hz}, \mathrm{H}-3,3$ '), 5.96 (2H, m, H-8, 8'), 5.09 (2H, d, $J=1.5$ Hz, H-9a, 9a'), 5.04 (2H, d, $\left.J=1.5 \mathrm{~Hz}, \mathrm{H}-9 \mathrm{~b}, 9 \mathrm{~b}^{\prime}\right), 3.34$ (4H, d, br, $\left.J=4.5 \mathrm{~Hz}, \mathrm{H}-7,77^{\prime}\right) .{ }^{13} \mathrm{C}-\mathrm{NMR}$ $\left(125 \mathrm{~Hz}, \mathrm{CDCl}_{3}\right) \delta: 151.3\left(\mathrm{C}-2,2^{\prime}\right), 137.7\left(\mathrm{C}-8,8^{\prime}\right), 133.2\left(\mathrm{C}-5,5^{\prime}\right), 131.4\left(\mathrm{C}-6,6^{\prime}\right), 129.9\left(\mathrm{C}-4,4^{\prime}\right)$, 124.6 (C-1, 1'), $116.9\left(\mathrm{C}-3,3^{\prime}\right), 115.9\left(\mathrm{C}-9,99^{\prime}\right), 39.5$ (C-7, 7'). By comparing with reference data [7], peak 1 was identified as magnolol.

Peak 2: white powder. ESI-MS $(\mathrm{m} / \mathrm{z}): 347[\mathrm{M}+\mathrm{Na}]^{+} .{ }^{1} \mathrm{H}$ NMR $\left(500 \mathrm{~Hz}, \mathrm{CDCl}_{3}\right) \delta: 7.88(1 \mathrm{H}, \mathrm{d}, J$ $\left.=16.0 \mathrm{~Hz}, \mathrm{H}-7^{\prime}\right), 7.58\left(2 \mathrm{H}, \mathrm{m}, \mathrm{H}-2^{\prime}, 6^{\prime}\right), 7.40\left(3 \mathrm{H}, \mathrm{m}, \mathrm{H}-3^{\prime}, 4^{\prime}, 5^{\prime}\right), 6.72\left(1 \mathrm{H}, \mathrm{d}, J=16.0 \mathrm{~Hz}, \mathrm{H}-8^{\prime}\right)$, $6.49(2 \mathrm{H}, \mathrm{s}, \mathrm{H}-2,6), 5.99(1 \mathrm{H}, \mathrm{m}, \mathrm{H}-8), 5.17(1 \mathrm{H}, \mathrm{d}, J=1.5 \mathrm{~Hz}, \mathrm{H}-9 \mathrm{a}), 5.12(1 \mathrm{H}, J=1.5 \mathrm{~Hz}, \mathrm{H}-9 \mathrm{~b})$, $3.82\left(6 \mathrm{H}, \mathrm{s}, 2 \mathrm{xOCH}_{3}\right) .{ }^{13} \mathrm{C}-\mathrm{NMR}\left(125 \mathrm{~Hz}, \mathrm{CDCl}_{3}\right) \delta: 164.9\left(\mathrm{C}-9^{\prime}\right), 152.2(\mathrm{C}-3,5), 146.5\left(\mathrm{C}-7^{\prime}\right)$, 138.7 (C-1), 137.0 (C-8), 134.5 (C-1'), 130.6 (C-4'), 129.0 (C-3', 5'), 128.4 (C-2', 6'), 127.0 (C-4), $117.1\left(\mathrm{C}-8^{\prime}\right), 116.4(\mathrm{C}-9), 105.3(\mathrm{C}-2,6), 56.2\left(2 \times \mathrm{OCH}_{3}\right), 40.8(\mathrm{C}-7)$. Compared with the data given in reference [7], peak 2 was identified as difengpin.

Peak 3: white powder. ESI-MS $(\mathrm{m} / \mathrm{z}): 397[\mathrm{M}-\mathrm{H}]^{-} \cdot{ }^{1} \mathrm{H}$ NMR $\left(500 \mathrm{~Hz}, \mathrm{CDCl}_{3}\right) \delta: 7.18(2 \mathrm{H}, \mathrm{d}, J=$ $\left.9.0 \mathrm{~Hz}, \mathrm{H}-3^{\prime}, 5^{\prime}\right), 7.13$ (1H, dd, $\left.J=9.0,2.0 \mathrm{~Hz}, \mathrm{H}-5 "\right), 7.12$ (2H, d, $\left.J=2.0 \mathrm{~Hz}, \mathrm{H}-3 "\right), 7.01$ (1H, d, $J$ $\left.=8.5 \mathrm{~Hz}, \mathrm{H}-6^{\prime \prime}\right), 6.99\left(2 \mathrm{H}, \mathrm{d}, J=8.5 \mathrm{~Hz}, \mathrm{H}-2^{\prime}, 6^{\prime}\right), 6.90(1 \mathrm{H}, \mathrm{d}, J=2.0 \mathrm{~Hz}, \mathrm{H}-5), 6.72(1 \mathrm{H}, \mathrm{d}, J=2.0$ Hz, H-3), 5.86-6.04 (3H, m, H-8, 8', 8"), 5.02-5.12 (6H, m, H-9, 9' 9"), 3.38 (4H, d, J=6.0 Hz, H-7', $\left.7^{\prime \prime}\right), 3.29(2 \mathrm{H}, \mathrm{d}, J=6.5 \mathrm{~Hz}, \mathrm{H}-7),{ }^{13} \mathrm{C}-\mathrm{NMR}\left(125 \mathrm{~Hz}, \mathrm{CDCl}_{3}\right) \delta: 154.6\left(\mathrm{C}-1^{\prime}\right), 151.8$ (C-1"), 144.2 (C-2), 141.7 (C-1), 137.8 (C-8'), 137.3 (C-8), 137.1 (C-8"), 135.8 (C-4'), 133.3 (C-4"), 132.7 (C-4), 131.0 (C-3"), 130.0 (C-3'), 129.7 (C-5'), 129.7 (C-5"), 126.4 (C-5), 125.6 (C-6), 125.0 (C-2"), 118.5 (C-2'), 118.5 (C-6'), 117.8 (C-3), 117.5 (C-6"), 116.0 (C-9"), 116.0 (C-9'), 115.6 (C-9), 39.5 (C-7), 39.5 (C-7"), 39.4 (C-7'). Comparing the above data with literature [8], peak 3 was identified as isodunnianol. 


\section{Conclusions}

Three main lignans were isolated from the anti-inflammatory extract of Illicium difengpi by one step HSCCC separation. Among of them, isodunnianol was isolated from this plant for the first time. The study results described above showed the biphasic solvent systems (1:0.3:1:0.2, v/v) was very suitable for separation of three compounds. Moreover, the separation method may be applied for the scale-up production.

\section{Acknowledgements}

This work was financially supported by the Guangxi Scientific Research and Technology Development Program (14125008-2-23), the Foundations of Guangxi Key Laboratory of Functional Phytochemicals Research and Utilization (ZRJJ2014-2), and the Bagui Scholar Program of Guangxi.

\section{References}

[1] China Pharmacopoeia Committee, Pharmacopoeia of People's Republic of China, 2015, p. 123.

[2] H. P. Deng, L. Sun, Z. X. Xi, X. Li, C. Chen and L. N. Sun: J. Pharm. Practice Vol. 30 (2012), p. 8-13.

[3] Y. Ito: J. Chromatogr. A Vol. 1065 (2005), p. 145-168.

[4] A. L. Sun, F. Lei, R. M. Liu: Chin. J. Anal. Chem Vol. 33 (2005), p. 1016-1018.

[5] X. Wang, J. H. Liu, C. G. Cheng and C. C. Zheng, CN. Patent, 200410036087.4, (2005).

[6] F. Oka, H. Oka, Y. Ito: J. Chromatogr. A Vol. 538 (1991), p. 99-108.

[7] P. Huang, M. Yang, M. X. Lai, X. Z. Zheng, S. Nisimasa, and C. Naknisi: Acta. Pharm. Sinica Vol 31 (1996), p. 278-281.

[8] P. J. Lv: Henan: Henan University, (2015), p. 23-24. 